\title{
Postmodernism in Russian pedagogical discourse
}

\author{
Olga Fedotova ${ }^{1, *}$ and Vladimir Latun ${ }^{2}$ \\ ${ }^{1}$ Don State Technical University, Gagarin Sq, 1, Rostov on Don, 344003, Russia \\ ${ }^{2}$ Southern Federal University, Bolshaya Sadovaya Str., 105, Rostov on Don, 344000, Russia
}

\begin{abstract}
The article analyzes the state and level of theoretical elaboration of the issues of pedagogy of the postmodern era in the Russian scientific literature. Based on the analysis of the content of publications posted in the Russian leading bibliographic resource - bibliographic database of scientific publications "The Russian Science Citation Index" - the ratio of publications devoted to the problems of postmodernism in non-pedagogical and pedagogical discourse is revealed. There are established the main clusters, which include publications on general problems of postmodern pedagogy, problems of meta-postmodern pedagogy and anti-pedagogy. The interpretive approach allows us to prove that in Russian pedagogy, critical and analytical consideration of foreign pedagogical arrays dominates. At the same time, there are first attempts to determine the author's position on the creation of Russian postmodern pedagogy, which at present is not completely methodologically entrusted. The arguments used by the authors to substantiate postmodern pedagogy are very exotic and fully correspond to the principle "Anything goes", which is a methodologically regulating postmodern pedagogy.
\end{abstract}

\section{Introduction}

In the history of pedagogical ideas, much attention is paid to the issues based on the development of knowledge, addressed in the formulation and solution of educational problems in each specific historical period. The history of education and pedagogy has passed a difficult path in which researchers draw a clear dividing line between the pre-scientific and scientific periods of its development. Dynamic processes take place in modern education and pedagogical knowledge that ensures its implementation. They are characterized by renowned scientists as a paradigm shift. Both in Russian and in foreign scientific knowledge, various names and designations of time periods for the spread of methodological paradigms are proposed. However, summing up the positions related to the modern period of the development of science, one can find the common thing, that has been noted by researchers in relation to the modern stage of science. At the same time, changes in worldview positions play an extremely important role in the implementation and development of scientific activity. The asserting post-non-classical rationalism, which has replaced non-classical rationality, is not only significantly expanded, but also complicated the world outlook of

\footnotetext{
* Corresponding author: fod1953@yandex.ru
} 
modern man. There was a need to develop new methodological principles and values that characterize the qualitative originality of pedagogy.

The problems of the development of scientific knowledge in the field of pedagogy are increasingly analyzed from the standpoint of the transition to the methodological positions of the era of post-non-classical science. At the same time, science becomes, along with art and religion, only one of the spheres of social consciousness, an important source of new knowledge [1 - 5]. It cannot be denied that postmodern projections in pedagogy arose outside the position of the ideological and geographical boundaries of modern Russia. However, at present we are seeing the emergence of scientific research and works performed in a journalistic style, terminologically related to postmodern pedagogical discourse.

\section{Methodology}

The purpose of the study is to determine the qualitative uniqueness of the approaches of Russian scientists to the topic of postmodernism, to analyze the content and forms of presentation of pedagogical knowledge in the discourse of a new issue.

Methodology and logic of the research. Approaches to the analysis of the phenomenon of postmodernism in its pedagogical projection are complex combinations of traditional and non-standard ways of accessing pedagogically significant content, the levels of its analysis, the definitions of new phenomena and their terminological fixation.

Therefore, in relation to Russian pedagogy, it seems appropriate to consider those pedagogical publications that have already been indexed on the leading Russian scientometric resource, meaningfully and terminologically related to the problems of postmodernism in their chronological and meaningful aspects.

The research includes two stages.

Materials. The source of empirical data is the leading Russian scientific resource - a bibliographic database of publications of Russian scientists, combined with The Russian Science Citation Index. It accumulates more than 12 million publications of Russian authors. The Russian-language sources were analyzed - articles and monographs, including those published in the countries of the former USSR.

The sample of publications is 300 units. This number avoids the inevitable duplication and repetition of article titles, taking into account the names of co-authors in the publications presented in this resource

Research Methods are various types of analysis (cluster analysis, content analysis, comparative analysis) [6], interpretation, generalization, abstraction [7]. When conducting content analysis, the concept of "postmodern pedagogy" was assigned to a semantic unit, and the number of thematic articles on an electronic resource reflecting this problem was established in units of count.

The results were entered into coding tables. To visualize the results, the graphic capabilities of the EXCEL and PAINT programs were used [8].

\section{Results and discussion}

The first stage of the research is devoted to the analysis of the sample, which is presented on the resource of the Russian Science Citation Index for the search query "postmodern pedagogy". Of the three hundred publications issued by the resource for this search query, those whose titles did not contain the term under study and included such definitions as "modern", "innovative", "modernization" were excluded. In addition, the number of the studied publications did not include those related to philosophical, sociological, cultural, historiographic problems. The results are shown in Fig. 1. 


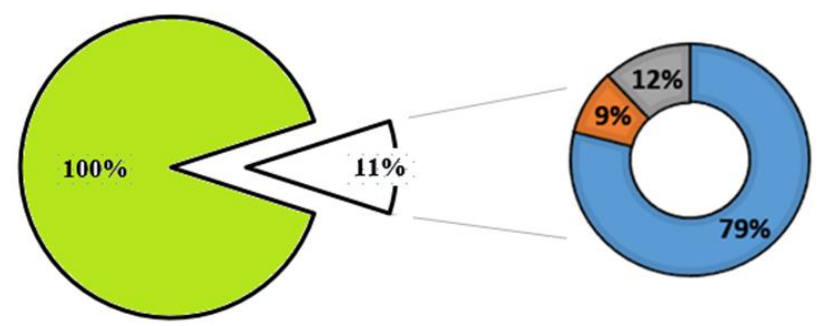

Fig. 1. Distribution of the array of publications in the electronic resource of the Russian Science Citation Index (in percent).

Where: $\square$ - the total number of publications for the search query "postmodern pedagogy"; $\square$ - publications that substantively and thematically reveal the problems of postmodern pedagogy; $\square$ - general problems of postmodern pedagogy; $\Pi$ - problems of meta-modern pedagogy; $\square$ - problems of anti-pedagogy.

As shown in the Figure 1, the significant number of Russian publications posted on the resource is not associated with the problems of postmodern pedagogy. Basically, these are works that reveal ways to improve the educational process based on traditional approaches and educational technologies. Some articles reflect the problems of the emergence of postmodern ideas in the works of representatives of post-non-classical philosophy. It is possible to single out only 33 works ( $11 \%$ of the total array) devoted to pedagogical problems themselves.

Cluster analysis of the content of these publications allowed us to single out three thematic groups: general problems of postmodern pedagogy, meta-modern pedagogy and anti-pedagogy. They are presented extremely unevenly - the prevailing critical and analytical discourse concerning the body of knowledge that has developed in foreign theory and practice.

The second stage of the research is devoted to the consideration of the peculiarities of the presentation of the issues of postmodern pedagogy by Russian authors in the debatable, analytical and creative aspects. The study of the content of publications has shown that much attention is paid to discussing the issue of whether Russian pedagogical thought has moved to the position of post-non-classical science. A negative answer to this question is given by V.L. Benin [9]. This author in his work arguably proves that in the organization and expert assessment of the results of pedagogical research, despite the intensified incorporation of terminology associated with synergetics as a new methodological guideline, the use of metric characteristics plays a decisive role. The author concludes that the use of a newfangled terminological series and the proclaimed new paradigmatic approaches do not yet mean a transition to the positions of post-non-classical science.

A different position is presented in the textbook by A.V. Voznyuk [10]. The author uses as synonyms the concepts of "postmodern" and "post-non-classical" pedagogy [10, p. 102]. The author gives the following definition: "post-non-classical pedagogy is the pedagogy of educational synthesis and integration, which ensures both the integration of the contentmethodological aspect of the pedagogical process and the synthesis of all its participants (in the context of the synthesis of the socio-pedagogical environment). Post-non-classical pedagogy is based on the post-non-classical type of scientific rationality (end of the twentieth century), within which the subject and the object are understood as an integral indivisible complex, and in the process of cognition, both means and operations and value-target characteristics of scientific activity begin to be taken into account" [10, p. 102].

Supporting the author in his attempt to define postmodern pedagogy, we note that A.V. Voznyuk declares that he has realized the possibility of a step-by-step substantiation of postnon-classical pedagogy. 
In total, the author presents 56 "steps", many of which duplicate each other. Synergetics is declared "the principle of pedagogical paradoxology" [10, p. 87], and the author's concept of "pedagogical synergetics" is proposed along with the "pedagogy of near-death states" [10, p. 432-450], "noo-sphere-resonant pedagogy" [10, p. 502-532], "the pedagogy of" zero states "and lucid dreams" [10, p. 594 - 846], "metamorphosis pedagogy" [10, p. 729-739] and many others, which are distinguished by the unconditional non-triviality of both names and their content.

Without challenging the right of everyone to state their original positions, including to offer the author's vision of the directions for the development of pedagogy, as well as to point out factors of formative influence that are non-traditional for modern scientific thought, we note that A.V. Voznyuk appears to be untenable on several grounds of a formal and conceptual plan. On formal logical grounds, the arguments concerning the justification of post-non-classical pedagogy are very nontrivial. The proof is the verses of V. Soloviev (without specifying the poetic source) [10, p. 93], a reproduction of the painting "The Knight at the Crossroads" (without reference to the author - Viktor Vasnetsov) [10, p. 91].

In particular, this picture is used to illustrate one "of the aspects of the Slavic cultural code, which expresses the spontaneously creative nature of behavior and knowledge of the world" [10, p. 91]. The fact of the presence of scientific and theoretical thinking, according to the author, "can be illustrated with the lines of a genius poet ("genius is a friend of the paradox")" without specifying the name of the famous author of these poetic lines [10, p. 86] alongside N. Bohr's statements that a true idea should be quite crazy.

The work of S.A. Ushakin [11], which also attempts to define the subject of postmodern pedagogy: "while stating the defects of modern education, it should be clarified that the essence of postmodern pedagogy, and the policy of multiculturalism in general, is not to introduce more heterogeneous elements into the course of "general" history, but in learning to see this "course" from the greatest possible number of positions "[11, p. 7]. It is obvious that in order to clarify his thoughts S.A. Ushakin uses a "negative definition" of postmodern pedagogy.

Russian authors introduce the term "meta-modern", which is new for Russian pedagogy, understanding it as a category that fixes the state of society in the period that should follow after the postmodern period [12]. For this, the authors use the basis of the terminological cliché "metamodernism" proposed by M. Zavarzadeh [13]. V.G. Bezrogov and V.K. Pichugina are guided by the thoughts expressed by P.T. Webb and K.N. Gulson [14] about the space-time compression of modern reality, which does not allow to slowly implement certain educational strategies. The authors consistently carry out the idea that the modern "student" (in the broad sense of the word) has an expanded choice of time and space for the implementation of consciously chosen tactics and practices of personal growth, professional development in lifelong education systems due to the expansion of the pedagogical reality itself.

Anti-pedagogy is analyzed by Russian author A. Ogurtsov [15] in a critical and analytical manner and for the first time acquaints Russian readers with the programmatic work of D. Lenzen [16] and the position of A. Miller [17].

\section{Conclusion}

Russian pedagogical thought is actively exploring new horizons of knowledge, which are based on the ideas of the philosophy of postmodernism. If, philosophically, the ideas of postmodernism are not new for Russian researchers, then the pedagogical problems have not yet been fully comprehended. With a certain degree of conventionality, it is possible to classify existing publications according to the criterion of theorists' efforts aimed at fixing or critical development of innovative trends in such spheres as science, art, education, and 
religion. There are two main positions in the complex of ideas presented in the Russian scientific and pedagogical discourse. The first thematic line is characterized by a critical and / or analytical approach to the set of ideas in the field of education and the theory of pedagogy, which is already presented in foreign pedagogical thought and educational practice. This approach expands the ideas of Russian teachers about new trends, processes, technologies being developed abroad and, to a certain extent, popularizes the ideas of postmodern pedagogy. The second approach is attempts to develop its own (author's) pedagogical concept.

Focusing on the postmodern maxim "Anything goes", the authors propose original, often bizarre and fundamentally extraordinary positions. Publications are mostly journal articles, and the only publication of a large volume of 1149 pages [10] cannot be unambiguously defined by genre - at the beginning of the publication it is stated that this is a textbook, at the end - as a scientific publication and at the same time a tutorial.

A general overview of the state of the problems of postmodern pedagogy in the Russian scientific and pedagogical discourse, not limited to the publications reviewed, indicates that the development and theoretical substantiation of a new stage in the development of pedagogical thought still awaits its solution.

\section{References}

1. O. Fedotova,V. Latun, S. Tlepcerishcheva, Dilemas Contemporaneos-Educacion Politica Y Valores 7, 20 (2019)

2. Anonymous, Speculum-A Journal Of Medieval Studies 5(1), 314 -313 (2020)

3. Y. Zeng, Annual International Academic Conference on Human Society and Culture (HSC) (Shenzhen, 2016).

4. Y. Li, International Conference on Informatization in Education, Management and Business (IEMB) (Guangzhou, 2014)

5. A. Thouki, European Religious Sites 10(12) (2019) https://www.mdpi.com/2077$1444 / 10 / 12 / 649$

6. O.D. Fedotova, O.P. Chigisheva, International Perspectives on Education and Society 26, 57-82 (2015)

7. L. Cohen, L. Manion, K. Morrison, Research methods in education $6^{\text {th }}$ edition (Routledge, NY, 2007)

8. J. Freeman, S. Walters, M. Campbell, How to display data (Blackwell Publishing, Massachusetts, USA, 2008)

9. V.L. Benin, Education and Science 6(95), 122 - 135 (2012)

10. A.V. Voznyuk, Postnonclassical frontiers of pedagogy of the future: a textbook (Koob publications, Zhytomyr, 2019)

11. S.A. Ushakin, Polis. Political Studies 4, 117-124 (1997)

12. V.G. Bezrogov, V.K. Pichugina, Socium and Power 6(50), 116-123 (2014)

13. M. Zavarzadeh, Journal of American Studies 9(1), 69-83 (1975)

14. P.T. Webb, K.N. Gulson, Educational theory 63(1), 51-67 (2013)

15. A. Ogurtsov, Higher education in Russia 5, 79-86 (2002)

16. D. Lenzen, Journal for pedagogy 29, 75 - 91 (1992)

17. G.B. Kornetov, Historical and pedagogical yearbook. 2018 Series "Historical and pedagogical knowledge", 102-120 (2018) 